\title{
Consultant Psychiatrists: Their Career Choice and Training
}

\author{
Peter Brook, Consultant Psychogeriatrician, Fulbourn Hospital, Cambridge
}

When, and for what reasons, do doctors decide to specialize in psychiatry? Having committed themselves, how adequate do they find their training? Is the general level of their training improving as a result of the efforts of the Royal College of Psychiatrists and of the Joint Committee on Higher Psychiatric Training (JCHPT)? These were the questions asked of consultants in general psychiatry newly appointed between 1 October 1978 and 30 September 1981.

As in similar surveys carried out since 1966 (Brook, 1972; 1974a; 1974b; 1977; 1978; 1980; 1981a; 1981b), the consultants whose responses are presented here did not include those with a major commitment in psychotherapy, child and adolescent psychiatry, mental handicap and forensic psychiatry, but did include psychogeriatricians, general psychiatrists with a special interest and general psychiatrists in university or research posts holding honorary NHS appointments.

The previous studies had shown an initial improvement after an earlier survey on consultants appointed 1963-66 (Royal Medico-Psychological Association, 1969), but changes remained slight until the survey of those appointed 1975-78, which did show some progress over the previous three years, notably in the fields of individual psychotherapy, community work and forensic psychiatry. Has there been further progress in the past three years? Do many of the consultants still express the view that they had had insufficient experience in the psychiatric specialties in order to make an informed choice about their careers in psychiatry?

A postal questionnaire asked the consultants in detail about their training. (Further information is available from the author on request.) When considering the question of adequacy, respondents were asked to 'use the criterion of your being prepared for a consultant post'. They were also asked when they had made a definite decision to enter the specialty, and what were their opinions as to whether, during the course of their training, they had received experience in a sufficient number of specialties to be able to make an objective choice whether or not to work in those areas.

\section{Findings}

Of the 123 who were eligible to the questionnaire, 114 replied-a response rate of 92.7 per cent. Twenty-two (19 per cent) were women. Thirty-one ( 27 per cent) had qualified abroad, two-thirds of whom qualified in the Indian sub-continent.

For the purpose of analysing training experience, a subdivision was made based on the three types of hospital or institution in which consultants had spent most time in the registrar grade. The three types were: (1) units which were part of undergraduate teaching hospitals $(n=52)$; (2) psychiatric hospitals and non-teaching DGH units $(n=52)$; (3) the Bethlem Royal and Maudsley Hospitals (The Maudsley) $(n=7)$. Two consultants had received their training while in the Armed Forces and one had received his entire training overseas.

Fifty-four of the consultants had been appointed from the grade of senior registrar, 29 from locum consultant posts, 20 from lecturer posts, 4 had been associate specialists and 6 from other jobs; one had been a senior hospital medical officer. Ten respondents had been appointed to research or university posts with an honorary contract. This meant there had been a net inflow of 13 psychiatrists (23-10) moving from a university or research post to an NHS one- just over four a year.

The proportion of those appointed from non-training grades-excluding locum consultants-was 4 per cent. Sixty-four consultants (56 per cent) were in posts with special interests; 27 of these had a major interest in psychogeriatrics, and a further five a minor interest. Ten had a special interest in rehabilitation, nine in drug and alcohol dependence, six in mental handicap, five in psychotherapy and two in forensic psychiatry.

Fifteen consultants had decided to enter their specialty before entering school and while in medical school.

Consultants were asked whether they had had enough experience in general psychiatry and the psychiatric specialties while in medical school and during training to make an informed decision about their choice. The percentages who indicated that they had obtained sufficient experience were 95 for general psychiatry $(1975=82$ per cent), 69 for psychogeriatrics ( $1975=42$ per cent), 30 for handicap $(1975=20$ per cent $), 50$ for child psychiatry $(1975=39$ per cent), 46 for forensic $(1975=33$ per cent $)$, and 56 for psychotherapy $(1975=48$ per cent). The consultants' experience of training and teaching are given in Tables I and II.

Three years ago the question was asked whether the efforts of the College and the JCHPT to improve postgraduate training in psychiatry were producing good results (Brook, 1980). The answer at that time was a qualified 'yes'. Has there been a further improvement in the past three years? Again, the answer must be 'yes'-rather more firmly this time-and this applies most clearly to experience in psychogeriatrics, long-stay patients, child and adolescent psychiatry, forensic psychiatry, psychology, neurophysiology, epidemiology, teaching experience with postgraduates and research. On the other hand, there seems to be less satisfaction with training in interviewing techniques and individual psychotherapy. Of the fourteen particularly poor 
TABLE I

Training in clinical areas - response 1 only. By year of survey and for '1978' group by type of hospital where trained and country of qualification

\begin{tabular}{|c|c|c|c|c|c|c|c|c|c|}
\hline & \multirow[b]{2}{*}{$\begin{array}{c}1966 \\
\text { group } \\
n=108\end{array}$} & \multirow[b]{2}{*}{$\begin{array}{c}1969 \\
\text { group } \\
n=125\end{array}$} & \multirow[b]{2}{*}{$\begin{array}{c}1972 \\
\text { group } \\
n=164\end{array}$} & \multirow[b]{2}{*}{$\begin{array}{c}1975 \\
\text { group } \\
n=161\end{array}$} & \multicolumn{5}{|c|}{1978 group } \\
\hline & & & & & $\begin{array}{c}\text { All } \\
\mathrm{n}=111\end{array}$ & $\begin{array}{c}\text { Maudsley and } \\
\text { Teaching Hosp. } \\
\qquad n=59\end{array}$ & $\begin{array}{l}\text { Psych. } \\
\text { Hosp. } \\
n=52\end{array}$ & $\begin{array}{l}\text { Hom } \\
\text { Grad. } \\
n=81\end{array}$ & $\begin{array}{c}\text { Overseas } \\
\text { Grad. } \\
\mathbf{n}=\mathbf{3 0}\end{array}$ \\
\hline Interviewing techniques & 63 & 62 & 57 & 64 & 58 & 56 & 60 & 54 & 67 \\
\hline $\begin{array}{l}\text { Work with psychogeriatric patients } \\
\text { "Work with long-stay patients other }\end{array}$ & 44 & 42 & 43 & 48 & 59 & 58 & 62 & 58 & 63 \\
\hline $\begin{array}{l}\text { than geriatric } \\
\text { 'Rehabilitation activities, eg }\end{array}$ & 44 & 47 & 46 & 48 & 57 & 58 & 56 & 53 & 67 \\
\hline occupational/industrial therapy & 30 & 36 & 36 & 41 & 40 & 41 & 39 & 36 & 50 \\
\hline Individual psychotherapy & 47 & 48 & 50 & 62 & 58 & 68 & 46 & 62 & 47 \\
\hline $\begin{array}{l}\text { Group psychotherapy } \\
\text { Other methods of psychological treatment, }\end{array}$ & 41 & 42 & 46 & 49 & 54 & 59 & 48 & 54 & 53 \\
\hline eq behaviour therapy, hypnotherapy & 28 & 26 & 30 & 32 & 38 & 37 & 39 & 37 & 40 \\
\hline Ward consultation in general hospitals & 61 & 62 & 60 & 62 & 60 & 59 & 62 & 57 & 70 \\
\hline Treatment and management of alcoholism & 44 & 49 & 56 & 58 & 66 & 71 & 60 & 67 & 63 \\
\hline $\begin{array}{l}\text { Treatment and management of addiction } \\
\text { Emergency work (acutely disturbed patients }\end{array}$ & 44 & 49 & 56 & 34 & 31 & 36 & 25 & 32 & 27 \\
\hline in casualty dept or in patient's home) &, 50 & 61 & 60 & 64 & 65 & 69 & 60 & 64 & 67 \\
\hline $\begin{array}{l}\text { Medico-legal (legal reports and sectioning) } \\
\text { Community work (including dvs, Part III }\end{array}$ & 38 & 46 & 47 & 50 & 54 & 63 & 44 & 56 & 50 \\
\hline $\begin{array}{l}\text { acco. LA day centres and hospital) } \\
\text { Work in a therapeutic community in }\end{array}$ & 18 & 32 & 21 & 38 & 39 & 32 & 46 & 36 & 47 \\
\hline hospital or day hospital & 41 & 46 & 43 & 41 & 44 & 44 & 44 & 43 & 40 \\
\hline
\end{tabular}

Percentages rounded

TABle II

Teaching in specialized areas of experience_response I only. By year of survey and for the '1978' group by type of hospital where trained and country of qualification

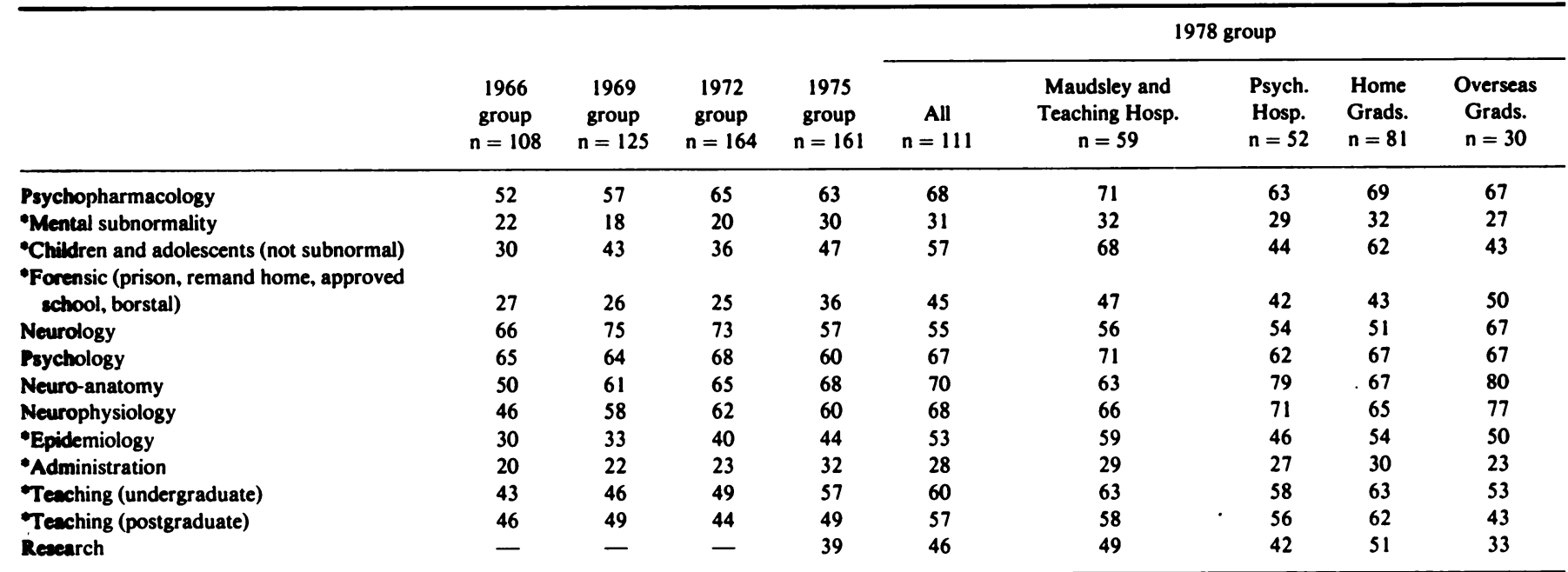

Percentages rounded 
areas listed in 1972 (indicated by an asterisk in the Tables), eight have now improved to the extent that more than 50 per cent of the consultants expressed complete satisfaction, still leaving six - rehabilitation, community work, subnormality, forensic psychiatry and administration below the line as originally drawn.

Because there were so few Maudsley trained respondents they were combined with the teaching hospital group. The Tables compare these consultants with those who had spent the majority of their time in a registrar grade in non-teaching hospitals. It will be seen that the teaching group did better than the psychiatric hospital group in nineteen areas, with the reverse holding true for six areas only. The advantages enjoyed by the teaching hospital group are particularly marked in training and experience in psychotherapy, alcoholism and addiction, medico-legal experience, child psychiatry, psychology and epidemiology. The psychiatric hospital group had a clear advantage only in work in the community and neuro-anatomy.

Home graduates reported more favourably on a number of areas of experience, particularly child psychiatry, teaching experience, research and psychotherapy. Conversely the overseas group reported better experience in interviewing techniques, work with long-stay patients, rehabilitation, ward consultation, community work, neurology, neuro-anatomy and neurophysiology.

All consultants were asked about their senior registrar training. Questions relating to senior registrar training were drawn up on the basis of the required training set out in the Second Report of the JCHPT (1980).

(a) Minimum of two half days a week for research, private study or some other type of clinical experience- 36 (40 per cent) replied no.

(b) Opportunities for experience of specialized areas such as child psychiatry, not done during general training-13 (15 per cent) replied no and a further 25 ( 28 per cent) said only to some extent.

(c) To learn the consultant's opinion of the SR's progress together with the SR's view on that posting as a training experience- 40 ( 45 per cent) replied no.

(d) Opportunity to participate in administration-21 (24 per cent) replied no.

(e) Taking part in teaching others-3 (3 per cent) replied no.

(f) Regular meetings with other senior registrars-15 (17 per cent) replied no.

(g) Acting up for consultant -6 ( 7 per cent) replied no.

(h) Experience in psychiatry of old age-18 (20 per cent) replied no.

(i) Experience in alcoholism-27 (30 per cent) replied no.

(j) The opportunity, time and supervision to undertake research $\longrightarrow$ (10 per cent) replied no.

(k) An effective link with a university department-13 (10 per cent) replied no.

(l) Effectiveness of the approval visits for Higher
Psychiatric Training in improving the quality of training-32 (36 per cent) replied no, while 5 (6 per cent) seemed uncertain.

\section{Comment}

The value of identical questions being posed to newly appointed consultants, over a period of fifteen years, is that it is possible to judge what advances in training have been achieved, in what areas gains have taken place, and where training falls short. However, three qualifications must be made. First, much of the study deals with opinions and not facts; second, these opinions will be modified by changes in expectations so that training which might have been judged satisfactory a dozen or so years ago may not be so now; and thirdly, the respondents are not typical of all who had psychiatric training, having won through to consultant posts by a combination of intelligence, determination, perseverance, luck and good judgement, as well as having had better than average training.

With these cautions in mind, what changes have occurred since the survey series began? The proportion of women rose sharply in the early 1970s, but now seems to be dropping off. In contrast, while the proportion of overseas graduates also showed a sharp rise in the early 1970s, this increase has been maintained. One change in the overseas qualified group is that in recent years a greater proportion have opted for psychiatry as a first choice rather than drifting in from other specialties

Concern has been expressed by the profession that manpower planning is being subverted by a substantial increase in the number of academic trainees who then obtain an NHS consultant post (Short Report-House of Commons, 1981). In psychiatry this fear would seem unfounded, with an average net inflow of only four a year moving from academic to NHS posts. One other noteworthy change is the substantial number of general psychiatrists appointed with a special interest, particularly in psychogeriatrics, but with rehabilitation also becoming more common.

Nearly two-thirds of the consultants still made their choice of specialty after qualifying - this highlights the potential importance of influencing career choice that psychiatrists have when they come in contact with junior doctors in hospital or general practice. There is a strong tide in favour of doctors having a period of undifferentiated experience before specialized training - the period of general professional training - which offers opportunities for attracting good recruits (DHSS, 1968; House of Commons, 1981).

Judged by their response to the question as to whether they had had enough experience in general psychiatry and the specialties to make informed decisions, the present cohort of consultants seem better informed than their predecessors. However, there is still much scope for improvement in the experience given in the specialties.

It is clear from the Tables that training is continuing to improve and the Approval Visits of the College and the 
JCHPT have produced good results. But it is disheartening to learn that the majority of consultants still rate their training in essential areas of activity - rehabilitation, work in the community and administration-as not completely satisfactory.

As well as a raising of the level of satisfaction with training, the gap in standards between psychiatric and teaching hospitals has narrowed, resulting, together with better opportunities to work in a teaching hospital, in a reduction of the discrepancies in training reported between home and overseas doctors. Nonetheless, discrepancies do still exist and still demand attention from the College and the JCHPT.

It is also disappointing that nearly half of the ex-senior registrars had not obtained the two half-study days each week recommended by the DHSS. Also, closer attention at senior registrar level would seem needed in administration, psychiatry of old age and alcoholism. Further consideration should also be given as to why so many ex-senior registrars felt that the JCHPT approval visits were not improving the quality of their training.

ACKNOWLEDGEMENTS

This study was funded by a grant from the Royal College of Psychiatrists. I would like to thank all those consultants who completed the questionnaire; Jane Boyce and Maria Silmon of the College's Education Department for organizing the survey; the DHSS, Scottish Home and Health Department and the Northern Ireland Health Authority for providing lists of consultants; and to Sue Chamberlain for her secretarial help.
REFERENCES

Brook, P. (1972) Consultant psychiatrists: The background and training of recently appointed consultants. British Journal of Medical Education, 6, 190-5.

(1974a) The postgraduate education and training of consultant psychiatrists. British Journal of Psychiatry, 124, 109-24.

(1974b) Psychiatrists: Background, career and career alternatives of a group of recently appointed consultants. British Journal of Psychiatry, 125, 1-9.

(1977) Psychiatric training: the consultants' view. British Medical Journal, i, 622-3.

(1978) Consultant psychiatrists: Who are they and where are they going? Medical Education, 12, 382-3.

(1980) Is psychiatric training improving? British Medical Journal, 281,787

(1981a) Postgraduate psychiatric training: The Royal College of Psychiatrists' survey of consultants in general psychiatry appointments 1975-1978. Medical Education, 15, 335-9.

- (1981b) The choice of career of consultant psychiatrists. British Journal of Psychiatry, 138, 326-8.

DHSS (1968) Report of the Royal Commission on Medical Educa tion. Cmnd 3569. London: HMSO.

House of Commons (1981) Social Services Committee, Fourth Report: Medical Education. London: HMSO.

Joint Committee on Higher Psychiatric Training (1980) Second Report. Royal College of Psychiatrists.

Royal Medico-Psychological Association (1969) Report on the questionnaire on postgraduate experience of training of consultants in adult psychiatry. British Journal of Psuchiatry, 115, 225-31.

\section{Senior Registrar Training in Alcoholism and Drug Dependence}

\section{Summary of a Report by a Working Party of the Dependence/Addiction Group*}

The working party was set up in November 1981 to review current senior registrar training in alcoholism and drug dependence, and to make recommendations for the future. It sought the views of all known consultants in alcoholism and drug dependence, and their present and past senior registrars. Attention to this question is justified for the following reasons. First, the Manpower Working Party's report, Medical Manpower in the Psychiatric Specialties (Royal College of Psychiatrists, 1982), has recommended that the average District (i.e. a population of 200,000 ) should allocate about four consultant sessions to the 'dependencies',

The working party comprised Dr D. Black (DHSS observer), Dr A. H. Ghodse, Dr N. W. Imlah and Dr K. J. B. Rix (Convener). Copies of the full length report are available from the College. such sessions being provided by general psychiatrists with a special interest in alcohol or drug dependence or both. Secondly, appropriately trained applicants are needed for vacancies which occur in the existing regional and subregional alcoholism treatment units and drug dependence clinics. Thirdly, the Treatment and Rehabilitation Working Group of the government's Advisory Council on the Misuse of Drugs is likely to recommend an increase in the number of consultants specializing in drug dependence.

At present there are about twelve senior registrar posts in alcoholism and about five in drug dependence, although only one of the latter is full-time. Such provision of training posts is unlikely to be adequate.

\section{The appropriate locations of senior registrar training}

It is recommended that each Regional Health Authority in 